\title{
Editorial
}

\section{Retrasos en el procesamiento de los artículos: a la caza del revisor.}

Hola a todas y todos:

Entre los muchos mails que recibo como Editor de la revista Óptica Pura y Aplicada, hay unos que me generan especial sentimiento de impotencia y son los relacionados con los dilatados plazos de tramitación.

Aunque hemos adoptado diferentes medidas para acortar los tiempos, tales como sugerencia obligatoria de revisores o la designación de Editores Asociados especializados en los temas, vemos cómo éstos no se acortan y un artículo tarda un mínimo de 6 meses en ser revisado. Lamentablemente, es un tema que supera el ámbito de la revista Óptica Pura y Aplicada y afecta, cada vez más, a revistas internacionales de todas las áreas e índices de impacto. Yo mismo, como autor de artículos de investigación, he sufrido que revistas de alto impacto tarden hasta un año en enviarme la primera revisión.

La gran extensión del problema sirve para aliviar un poco el sentimiento de culpa, pero no evita que, como Editor y como autor, reflexione sobre el problema y trate, en la medida de mis posibilidades, de minimizar su impacto.

Son varios los motivos que a lo largo de los años he visto que provocan este retraso. En primer lugar, está la sobrecarga de trabajo. Hay épocas en que se reciben una gran cantidad de artículos que se juntan con el trabajo diario. Dado que nuestra capacidad de procesar trabajos es limitada, empezamos por los primeros que llegan unos y se van enviando. En el momento que se empiezan a recibir las primeras revisiones, la gestión de dichos artículos absorbe el poco tiempo disponible y los trabajos pendiente se van retrasando. Afortunadamente, este problema se solucionó incorporando a un conjunto de Editores Asociados. Ahora los trabajos se asignan a cada especialista y, dado que la carga de trabajo está distribuida, el problema ha disminuido. Sigue habiendo áreas más sobrecargadas que otras, pero creo que este aspecto del problema se ha solucionado o se ha reducido considerablemente.

Más o menos superado el problema de la carga de trabajo, en la actualidad, la mayor causa de retraso en Óptica Pura y Aplicada se debe a la falta de revisores. Pese a que pedimos tres revisores por artículo (que al final acabamos utilizando) y empleamos nuestra propia experiencia en el tema para contactar con revisores, en la mayoría de las ocasiones, la falta de respuesta es la situación más general. Los correos pidiendo revisiones se pierden en la avalancha diaria de información, se filtran y acaban clasificados como correo basura o, simplemente, se ignoran. Normalmente, pasados unos días, se realiza un segundo intento. A veces hay más suerte y, en general, no.

La segunda situación más habitual es la de rechazo, bien sea por falta de tiempo o por falta de conocimientos suficientes en la materia. En función del grado de confianza que tengamos con el revisor 
elegido podemos intentar forzar la situación y tratar de que saque tiempo para una revisión, pero esto suele ser la opción desesperada y muchas veces tampoco resulta.

Como resultado de todo esto, encontramos trabajos enviados hasta a 15 revisores diferentes sin respuesta positiva. Esto es descorazonador y provoca que los trabajos se pongan en cuarentena antes de volver a la caza del revisor, lo que, inevitablemente, alarga más los tiempos de proceso.

Mi recomendación a los Editores Asociados es que, si esto pasa, se centren en conseguir al menos una revisión más o menos completa y fiable y que ellos mismos como expertos o cercanos a la materia le echen un vistazo para, al menos, descartar fallos mayores, pero pese a toda nuestra buena voluntad, y que tratamos de evitar los tiempos excesivos, a veces todo lo que podría salir mal, sale mal y los atascos suceden.

Me consta que esto sucede en todas las revistas. He hablado con Editores de otras publicaciones, leído editoriales, y artículos especializados y, lamentablemente, es un mal generalizado. El buen revisor es una especie en peligro de extinción.

Posiblemente esto sea un síntoma más del colapso del sistema actual de "publicar o perecer" que hace que todo aquello no sea publicar, publicar y publicar no esté valorado. Nuestro trabajo consiste en investigar y en dar clase. Entre la investigación se encuentra la revisión de artículos, pero son tantas las peticiones, tanto el tiempo que consumen y tan escaso nuestro tiempo que es más fácil decir no o ignorar el mail de requerimiento. Además, pensamos ( $\mathrm{o}$ al menos yo lo hago) que no compensa hacer un trabajo para una editorial que cobra cantidades exorbitadas de dinero por un trabajo que ellas no realizan: se apropian nuestro contenido, del copyright, de nuestra experiencia y encima, pagamos por leer nuestros propios trabajos. Demasiados incentivos negativos para invertir nuestro precioso tiempo. Si a eso añadimos que Óptica Pura y Aplicada es una revista no impactada y que ejercer de revisor para proporciona pocos beneficios el resultado es el que ya he comentado.

No se muy bien cómo solucionar el problema, más que apelar a la confianza y la honradez de nuestro trabajo. Óptica Pura y Aplicada es una revista editada por una Sociedad Científica, sin apoyo Editorial que sobrevive gracias al esfuerzo de los socios. Nuestro interés es puramente científico y divulgativo y espero que estos principios todavía sirvan para que los investigadores alrededor del mundo nos presten su tiempo y revisen nuestros manuscritos. Me gusta pensar que al final ese sentimiento prevalece y que al final llegará un revisor número 16 me responderá que SI puede revisar el artículo.

Muchas gracias a todos los revisores anónimos que con su tiempo contribuyen a que la ciencia siga en marcha y a los abnegados autores que esperan, pacientemente nuestra notificación.

Un saludo y buenas fiestas.

Alicante, diciembre 2018

David Mas Candela

Editor de Óptica Pura y Aplicada

DOI: $\underline{\text { http://dx.doi.org/10.7149/OPA.51.4.i }}$ 